\title{
Caracterização das vítimas de acidentes de trânsito atendidas em um hospital de referência do estado de Roraima
}

RESUMO | Analisar as características das vítimas de acidentes de trânsito atendidas no Hospital Geral de Roraima (HGR). Trata-se de uma pesquisa exploratória, descritiva, com abordagem quantitativa. Foi realizada no HGR - no setor do grande trauma (GT), na cidade de Boa Vista, Roraima, com uma amostra composta por 177 pacientes. Teve parecer favorável de número: 1.255.952, CAAE: 41787414.6.0000.5302. As análises e tabulação dos dados foram realizadas por meio do pacote estatístico PASW (versão 18). A pesquisa revelou que os acidentes de trânsito (AT's) ocorreram com maior prevalência no sexo masculino, mais especificamente na população jovem na faixa etária entre 18-25 anos, o tipo de veículo mais relacionado com os AT's foi a motocicleta, a principal causa dos AT's foi a ultrapassagem. Conclui-se que é necessário uma reavaliação do Estado com relação aos determinantes sociais da saúde e às leis que visam sua responsabilização por um trânsito mais seguro.

Palavras-chaves: acidentes de trânsito; causas externas; vítimas.

ABSTRACT | To analyze the characteristics of traffic accident victims treated at the General Hospital of Roraima (HGR). It is an exploratory, descriptive research with a quantitative approach. It was performed at the HGR - in the major trauma sector (GT), in the city of Boa Vista, Roraima, with a sample of 177 patients. It had a favorable opinion number: 1,255,952, CAAE: 41787414.6.0000.5302. Data analysis and tabulation were performed using the PASW statistical package (version 18). The research revealed that traffic accidents (AT's) occurred with higher prevalence in males, more specifically in the young population aged 18-25 years, the type of vehicle most related to the AT's was the motorcycle, the main cause of the accidents. AT's was overdrive. It is concluded that a reassessment of the state is necessary regarding the social determinants of health and the laws that aim to make them responsible for safer traffic. Keywords: traffic accidents; external causes; victims.

RESUMEN | Analizar las características de las víctimas de accidentes de tránsito atendidos en el Hospital General de Roraima (HGR). Es una investigación exploratoria, descriptiva con un enfoque cuantitativo. Se realizó en el HGR, en el sector de trauma mayor (GT), en la ciudad de Boa Vista, Roraima, con una muestra de 177 pacientes. Tenía un número de opinión favorable: 1.255.952, CAAE: 41787414.6.0000.5302. El análisis de datos y la tabulación se realizaron utilizando el paquete estadístico PASW (versión 18). La investigación reveló que los accidentes de tránsito (AT) ocurrieron con una mayor prevalencia en los hombres, más específicamente en la población joven de 18-25 años, el tipo de vehículo más relacionado con los AT fue la motocicleta, la principal causa de los accidentes. El AT estaba saturado. Se concluye que es necesaria una reevaluación del estado con respecto a los determinantes sociales de la salud y las leyes que tienen como objetivo hacerlos responsables de un tráfico más seguro

Palabras claves: accidentes de tránsito; causas externas; víctimas.

\section{Mirely Ferreira dos Santos}

Enfermeira. Mestre em Ciências da Saúde pela UFRR, Especialista - Urgência e Emergência pela FIP/PB. Docente EBTT do Instituto Federal do Amazonas-IFAM/Atualmente em Exercício Provisório na Reitoria Instituto Federal de São Paulo/IFSP - Coordenadoria de Assistência à Saúde do Servidor - CSS

\section{Jacinta Ferreira dos Santos Rodrigues}

Mestre em Letras pela UFRR. Docente EBTT do Instituto Federal da Paraíba - IFPB

Recebido em: 03/07/2019

Aprovado em: 05/08/2019

\section{INTRODUÇÃO}

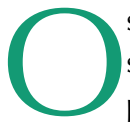

s acidentes de trânsito representam um dos principais problemas de saúde pública presente no Brasil devido a sua elevada taxa de morbimortalidade e repercussão social $^{1,2}$. O Ministério da Saúde classifica acidentes de trânsito como evento de causas externas que podem ser evitáveis e que não são intencionais, sendo um fenômeno multifatorial e que gera consequências variadas. Além de comover socialmente devido muitos dos desfechos graves e trágicos, os acidentes de trânsito geram impactos econômicos, principalmente, no sistema de saúde ${ }^{2,3}$. A Organização Mundial de Saúde (OMS), em 2009, registrou 1,3 milhão de mortes por acidente de trânsito em 178 países e apresentou estimativas de 1,9 milhão até 2020, caso o cenário mundial não mude no tocante à implementação de ações preventivas ${ }^{4}$.

O Brasil ocupa o $5^{\circ}$ lugar entre os países com o maior número de mortes no trânsito, precedido pela Índia, China, EUA e Rússia. O número de óbitos por Acidentes de Transporte Terrestre (ATT) no Brasil, em 2009, foi de 37.635, sendo a primeira subcausa dentro do grupo das causas externas para as faixas etárias de 10 a 14 anos e 40 a 59 anos. Nas demais, é a segunda causa de morte. A taxa de mortalidade por ATT no país em 2009 foi de 19,6 óbitos por cem mil habitantes, sendo de 32,6 para homens e 7,1 para mulheres. Observando-se as grandes regiões do país, as taxas mais elevadas ocorreram nas regiões Centro-Oeste e Sul com índices de 29,0 e 25,4 por cem mil habitantes, respectivamente ${ }^{5}$. 
Alguns fatores têm sido destacados na literatura médica como determinantes da origem e da gravidade dos acidentes de trânsito (AT's). São frequentemente citados a idade, o gênero, as condições socioeconômicas, o desrespeito à legislação de trânsito, sobretudo o abuso de velocidade e o consumo de bebidas alcoólicas prévios à direção de veículos automotores, normalmente associados à inadequada fiscalização no trânsito ${ }^{6}$.

O aumento exagerado dos veículos faz com que ocorra o aglomerado dentro do ambiente urbano da capital Boa Vista, em Roraima. Esse acréscimo reflete no aumento dos acidentes envolvendo motos, carros e pedestres, característica que vincula-se, entre outros, ao fato de que as avenidas e ruas da capital não apresentam estrutura condizente com tal aumento de veículos, seja pela falta de infraestrutura em algumas ruas, pela existência de ruas muito largas, excesso de rotatórias, além da própria engenharia do trânsito e da impunidade dos responsáveis.

Investigar a caracterização das vítimas de acidentes de trânsito é meta importante para identificar as melhorias na prevenção dos acidentes de trânsito e na qualidade de assistência prestada as vítimas. Nesse contexto, o presente artigo teve como objetivo analisar as características das vítimas de acidentes de trânsito atendidas em um Hospital de referência do Estado de Roraima, com o intuito de obter dados coerentes, seja para o fortalecimento de políticas públicas já existentes ou para a elaboração e formulação de futuras políticas voltadas para a prevenção desses agravos.
MÉTODO

Trata-se de uma pesquisa exploratória, descritiva, com abordagem quantitativa. Foi realizada no Hospital Geral de Roraima (HGR) - no setor do grande trauma (GT), na cidade de Boa Vista/RR.

A população foi constituída pelos pacientes atendidos no setor GT do HGR no período de dezembro de 2015 a janeiro de 2016. A amostra foi composta por 177 pacientes que foram atendidos durante o período da coleta enquadrados nos seguintes critérios de inclusão: Atendidos durante o período de dezembro de 2015 a janeiro de 2016, no setor do GT com diagnóstico de trauma devido a acidente de trânsito. Eram de ambos os sexos a partir da faixa etária dos 18 anos de idade. Tinham condições cognitivas e verbais, de forma a viabilizar o diálogo, essencial para o preenchimento dos instrumentos de coleta de dados (quando o paciente não possuía tais condições, era solicitado ao responsável/acompanhante que respondesse as perguntas, se assim estivesse de acordo).

Concordassem em participar da pesquisa, mediante assinatura do Termo de Consentimento Livre e Esclarecido (TCLE).

O estudo teve como critério de exclusão todos os pacientes atendidos no setor do GT que não tinham o diagnóstico de trauma por acidente de trânsito.

A coleta de dados foi realizada após autorização da instituição por meio do termo de autorização institucional. Houve três momentos distintos durante a realização da coleta de dados, a saber: o preenchimento do formulário da pesquisa dos pacientes que se enquadravam nos critérios de inclusão, momento este em que se coletavam os dados iniciais (questões sociodemográ- ficas: sexo, idade, estado civil, etc.) das vítimas na recepção do GT; o segundo momento era através da entrevista (questões sobre as características do acidente) com os pacientes ou com algum familiar (caso o paciente estivesse impossibilitado de se comunicar); o terceiro momento da coleta ocorreu através da consulta aos prontuários dos pacientes para averiguação dos tipos de lesões sofridas por meio do diagnóstico médico na ficha de atendimento.

As análises e tabulação dos dados foram conduzidas por meio do pacote estatístico PASW (versão 18). Os procedimentos incluíram estatísticas descritivas (medidas de tendência central) para fins de caracterização da amostra e ainda análises de distribuição de frequência das variáveis do estudo e os resultados foram representados em gráficos e tabelas para discussão e elaboração das considerações finais.

Esta pesquisa obedeceu rigorosamente às normas de Ética em Pesquisa contida na Resolução do Conselho Nacional de Saúde $N^{\circ}$ 466/2012, sobre pesquisas que envolvem seres humanos7. O estudo foi encaminhado ao Comitê de Ética em Pesquisa da Universidade Federal de Roraima para apreciação; sendo aprovado com CAAE n ${ }^{\circ}$ 41787414.6.0000.5302 e parecer favorável $\mathrm{n}^{\circ} 1.255 .952$.

\section{RESULTADOS}

A tabela 1 mostra a descrição detalhada da amostra pesquisada, em sua maioria eram: do sexo masculino $(62,1 \%)$, encontravam-se na faixa etária entre 18 a 25 anos (37,3\%), pardos (56,5\%), possuíam ensino médio completo (33,9\%), um salário mínimo mensal de renda $(67,2 \%)$ e solteiros $(52,0 \%)$.

Tabela 1 - Distribuição das características sociodemográficas das vítimas de acidentes de trânsito.

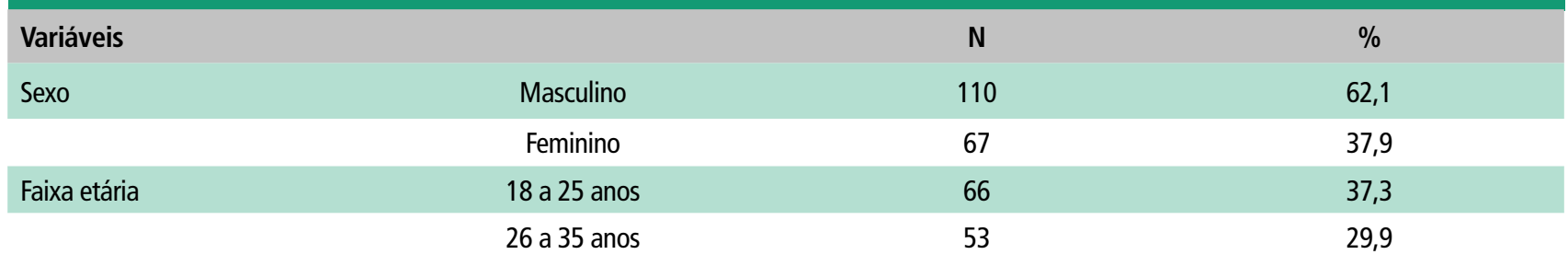




\begin{tabular}{|c|c|c|c|}
\hline \multirow[t]{5}{*}{ Variáveis } & & $\mathrm{N}$ & $\%$ \\
\hline & 36 a 45 anos & 27 & 15,3 \\
\hline & 46 a 55 anos & 13 & 7,3 \\
\hline & 56 a 69 anos & 13 & 7,3 \\
\hline & 70 anos ou mais & 5 & 2,8 \\
\hline \multirow[t]{3}{*}{ Renda Mensal } & Um salário mínimo mensal & 119 & 67,2 \\
\hline & Dois salários mínimos & 46 & 26,0 \\
\hline & Três a cinco salários mínimos & 12 & 6,8 \\
\hline \multirow[t]{5}{*}{ Raça/cor } & Branco & 45 & 25,4 \\
\hline & Pardo & 100 & 56,5 \\
\hline & Preto & 15 & 8,5 \\
\hline & Amarelo & 11 & 6,2 \\
\hline & Indígena & 6 & 3,4 \\
\hline \multirow[t]{7}{*}{ Escolaridade } & Analfabeto & 6 & 3,4 \\
\hline & Fundamental incompleto & 33 & 18,6 \\
\hline & Fundamental completo & 9 & 5,1 \\
\hline & Médio incompleto & 27 & 15,3 \\
\hline & Médio completo & 60 & 33,9 \\
\hline & Superior incompleto & 31 & 17,5 \\
\hline & Superior completo & 11 & 6,2 \\
\hline \multirow[t]{5}{*}{ Estado civil } & Solteiro & 92 & 52,0 \\
\hline & Casado & 46 & 26,0 \\
\hline & Viúvo & 1 & 0,6 \\
\hline & Divorciado & 10 & 5,6 \\
\hline & União estável* & 28 & 15,8 \\
\hline \multirow[t]{2}{*}{ Procedência } & Capital/Boa Vista-RR & 152 & 85,9 \\
\hline & Interior de RR & 25 & 14,1 \\
\hline \multirow[t]{5}{*}{ Ocupação } & Desempregado & 3 & 1,71 \\
\hline & Autônomo & 2 & 1,1 \\
\hline & Funcionário público & 28 & 15,8 \\
\hline & Serviços gerais & 67 & 37,9 \\
\hline & Outros* & 77 & 43,5 \\
\hline TOTAL & & 177 & 100 \\
\hline
\end{tabular}

Fonte: própria autora (2016).

Quanto ao tipo de veículo envolvido nos acidentes, verificou-se um dado preocupante com relação ao modo de veículo mais envolvido nos acidentes de trânsito no estado de Roraima, mais da metade das vítimas134 $(75,7 \%)$ estavam em motocicleta, 25 (14,1\%) em automó- vel, $13(7,3 \%)$ em bicicleta, 3 (1,7\%) em ônibus, $1(0,6 \%)$ em caminhonete e 1 $(0,6 \%)$ em micro-ônibus.

Em relação às causas dos AT's (tabela 2), é possível reconhecer que a preponderância foi de ultrapassagem $(18,6 \%)$, fato este que se associa, principalmente, aos jovens condutores de motocicletas, seguido de avanço de preferencial $(13,6 \%)$ foi observado que ambos condutores de automóvel e motocicleta realizaram esta imprudência. Em se tratando da causa consumo de bebida alcoólica $(12,4 \%)$ verificou-se que está intimamente relacionada com as 
seguintes causas de acidente de trânsito: perda de controle e excesso de velocidade. Sabe-se que o consumo do álcool é um agravante da situação, pois diminui a capacidade de mensuração do risco de acidente e de reação no momento do perigo.

No que tange às principais lesões (grá- fico 1) decorrentes de acidentes de trânsito observadas na amostra, a maioria das vítimas sofreu: ferimentos $(69,5 \%)$, contusão $(34,5 \%)$, politraumatismo $(20,9 \%)$, fratura $(19,2 \%)$; traumatismo em membros inferiores (15,3\%). Não foram constatados casos de esmagamento e amputação.

\begin{tabular}{|lcc|}
\hline Tabela 2 - Distribuição das vítimas de acidentes de trânsito segundo as causas. \\
\hline Causas dos acidentes & N & $\%$ \\
\hline Ultrapassagem & 33 & 18,6 \\
\hline Avanço de preferencial & 24 & 13,6 \\
\hline Consumo de bebida alcoólica & 22 & 12,4 \\
\hline Perdeu o controle & 20 & 11,3 \\
\hline Excesso de velocidade & 19 & 10,7 \\
\hline Outras & 13 & 7,3 \\
\hline Falha humana & 11 & 6,2 \\
\hline Defeito mecânico & 9 & 5,1 \\
\hline Desviar de um veículo & 8 & 4,5 \\
\hline Frear bruscamente & 5 & 2,8 \\
\hline Contramão & 4 & 2,3 \\
\hline Avanço de sinal vermelho & 4 & 2,3 \\
\hline Más condições das vias & 3 & 1,7 \\
\hline Manobra irregular & 2 & 1,1 \\
\hline Total & 177 & 100 \\
\hline
\end{tabular}

Fonte: própria autora (2016).

\section{Figura 1. Fluxograma e procedimentos utilizados na seleção dos estudos.}

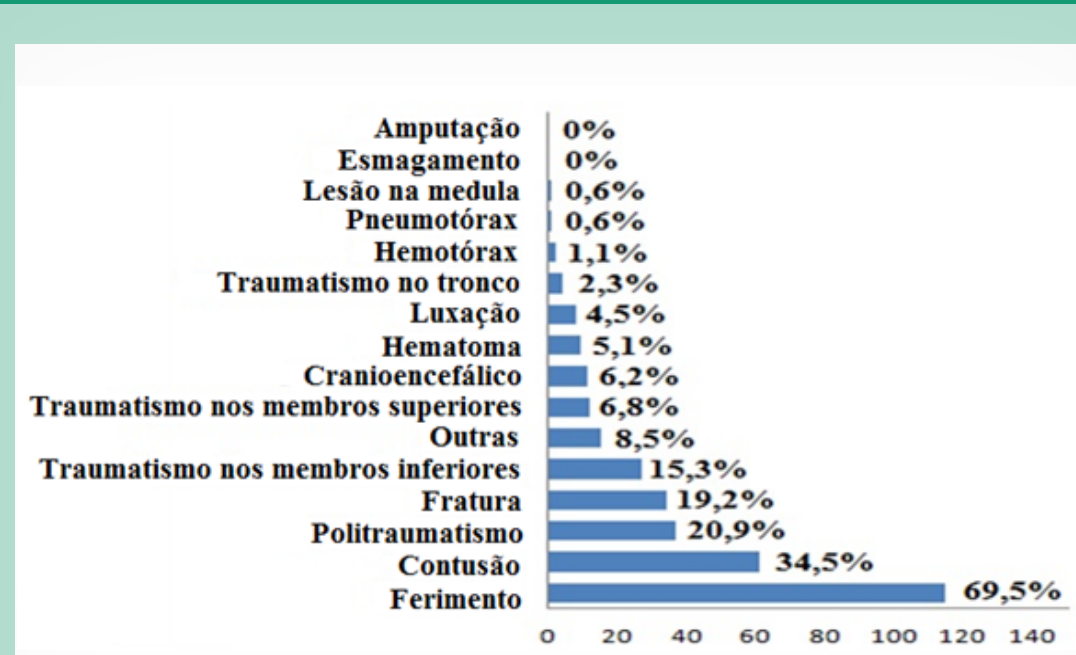

DISCUSSÃO

Conforme os resultados encontrados, há uma predominância de ocorrência de AT's no sexo masculino $(62,1 \%)$ das vítimas que foram atendidas no HGR de Boa Vista/RR, fato este que se evidencia em diversos outros estudos que demonstram uma tendência mundial de ocorrência dos AT's no sexo masculino. Pode-se corroborar esses dados com o estudo sobre caracterização dos fatores de risco para acidentes de trânsito em vítimas atendidas pelo serviço Móvel de Urgência, o qual demonstra em seus resultados que a predominância eram do sexo masculino $(78,9 \%) 8$. Já em um estudo também sobre vítimas de AT's, constataram que $(71,4 \%)$ eram sujeitos que pertenciam ao sexo masculino9. Outro estudo sobre os AT's realizado em São José do Rio Preto/ SP, mostra que $72,9 \%$ dos indivíduos pertenciam a esse gênero ${ }^{10}$.

Estudos mais recentes também demonstram esta tendência de os homens serem mais prevalentes que as mulheres nos AT's. O ser adulto jovem, do sexo masculino e que conduz motocicleta são fatores de risco para os acidentes, onde podem acarretar em lesões temporárias ou permanentes assim interferindo na qualidade de vida e gerando gastos públicos $^{6}$. Os jovens do sexo masculino são também as principais vítimas de acidentes com motocicleta, sendo que a maioria deles apresentaram lesões de baixa gravidade e bom prognóstico ${ }^{11}$.

No que diz respeito ao tipo de veículo mais envolvido nos acidentes, predominou os acidentes com motocicleta, que corroborou com os resultados ${ }^{12}$, onde o elevado percentual de envolvimento de motocicletas foi $(30,9 \%)$ quando comparado aos carros de passeio (18,9\%), vans ou caminhão $(2,3 \%)$ nos $\mathrm{AT}^{\prime}$ 's.

Sabe-se que a atual conjuntura econômica, bem como as diversas formas de financiamento, possibilita a aquisição de motocicletas. Associado ao crescente número desse tipo de veículo nas ruas e avenidas da capital Boa Vista/RR, desta- 
ca-se o desrespeito às leis de trânsito por parte dos motociclistas, assim como a velocidade excessiva e o uso de álcool, fatores estes que repercutem na gravidade dos casos de AT's.

Atribui-se essa maior prevalência de acidentes envolvendo motocicleta devido ser um veículo de maior exposição física dos passageiros. Existe também uma grande contribuição de práticas de transgressão de regras e sinalização de trânsito ${ }^{13,14}$.

Em relação às causas dos acidentes, o indivíduo alcoolizado tende a perder mais facilmente o controle do veículo, principalmente quando se trata de motocicletas, e o excesso de velocidade relaciona-se a gravidade do acidente, consequentemente quanto maior a velocidade do veículo, maiores são as chances de a vítima apresentar lesões mais graves devido ao impacto no momento do acidente.

O uso abusivo de álcool é um dos principais vilões dos AT's além de outros fatores, como drogas ilícitas, má sinalização, fiscalização reduzida, que contri- buem para o aumento de óbitos causados por AT's. Apesar de ter sido observado pequena redução $(2,67 \%)$ dos óbitos em acidentes após a Lei Seca, pode-se observar que em muitas regiões tiveram piora no número de óbitos, representando total de $43 \%$ do estado de São Paulo ${ }^{15}$.

Quanto aos vários tipos de lesões que podem se originar devido a um acidente de trânsito, percebe-se que variam com o grau de gravidade, podendo tornar-se, muitas vezes, incapacitante para o indivíduo de acordo com a forma em que ocorreu o acidente. As lesões decorrentes dos acidentes de trânsito além de poderem resultar em sequelas irreversíveis à vítima, também repercutem na vida dos familiares do vitimado e de toda sociedade, quando se refere aos aspectos econômicos e custos sociais resultantes do dano físico ou mental ocasionado pelo acidente.

Os traumatismos de cabeça e pescoço são considerados uma das formas mais graves de lesões, em virtude de sua letalidade e sequelas, salvo raras exceções, quando não mata deixa o acidentado com sequela motora, tais como, paraplegia e tetraplegia, isto é, a sequela do traumatismo de cabeça e pescoço geralmente conduz o acidentado para as estatísticas dos deficientes físicos. Esse tipo de lesão tem maior incidência nos acidentes com moto ou bicicleta e nos atropelamentos ${ }^{16}$.

\section{CONCLUSÃO}

Conclui-se que é necessário a implementação de programas de educação que visem à promoção e prevenção dos AT's com base no Código de Trânsito Brasileiro (CTB), sendo voltados para todos os públicos, desde as crianças até a terceira idade. A educação para o trânsito precisa melhorar e a fiscalização deve ser mais eficaz e permanente, não devendo ser praticada apenas esporadicamente. Além disso, sugere-se uma reavaliação do Estado com relação aos determinantes sociais da saúde e às leis que visam sua responsabilização por um trânsito mais seguro.

\section{Referências}

1. Almeida RLFD, Bezerra Filho JG, Braga JU, Magalhães FB, Macedo MCM, Silva KA. Via, homem e veículo: fatores de risco associados a gravidade dos acidentes de trânsito. Rev. Saúde Pública, São Paulo. 2013, 47 (4): 718 - 731. 2. Brasil. Ministério da Saúde. Secretaria de Vigilância em Saúde. Departamento de Vigilância de Doenças e Agravos Não Transmissíveis e Promoção da Saúde. Viva: Vigilância de Violências e Acidentes: 2013 e 2014. Brasília: Ministério da Saúde, 2017.

3. WHO - World Health Organization. Global Status Report on Road Safety. Geneva:WHO, 2015.

4. Waiselfisz JJ. Os novos padrões da violência homicida no Brasil. São Paulo: Instituto Sangari, 2012

5.Moraes Neto OL, Malta DC, Mascarenhas MDM, Duarte EC, Silva MMA, Oliveira KB, Lima CM, Porto DL. Fatores de risco para acidentes de transporte terrestre entre adolescentes no Brasil: Pesquisa Nacional de Saúde do Escolar (PeNSE). Ciência \&Saúde Coletiva. Rio de Janeiro. 2010; 15 (2): 3043 - 3052. 6. Trevisol DJ, Bohm RL, Vinholes DB. Perfil epidemiológico das pacientes vítimas de acidentes de trânsito atendidos no serviço de emergência do Hospital Nossa Senhora da Conceição em Tubarão, Santa Catarina. Sci. Med. Porto Alegre. 2012, 22 (3): 148 - 152.

7. Brasil. Ministério da Saúde. Comissão Nacional de Ética em Pesquisa. Conselho Nacional de Saúde (BR). Diretrizes e Normas regulamentadoras de pesquisa envolvendo seres humanos. Resolução $N^{\circ} 466 / 12$ de 12 de dezembro de 2012 - CNS. Brasilia, DF, 2012.

8. Santos SMJ, Souza MA, Rocha FL, Souza VP, Muniz MAS, Rodrigues JA. Caracterização dos fatores de risco para acidentes de trânsito em vítimas atendidas pelo serviço móvel de urgência. Rev. Enferm. UFPE. Recife, 2016, 10 (10), 3819 - 3824. 9. Barros AJD, Amaral RL, Oliveira MSB, Lima SC, Gonçalves EV. Acidentes de trânsito com vítimas: sub-registro, caracterização e letalidade. Cad. Saúde Pública, Rio de Janeiro. 2003, 19 (4): 979 - 986.

10. Santos MR, Soler ZASG. Vítimas do trânsito em São José do Rio Preto, São Paulo. Epidemiologia e Serviços de Saúde. 2007, 16 (2).

11. Ferreira TFA, Nápolis ACR, Lima CS, Araújo LC, Garcia CB, Lima PS, Sá DM, Silveira J. Estudo da gravidade dos pacientes vítimas de acidentes de trânsito atendidos pelo Hospital das Clínicas de Uberlândia de Dezembro de 2005 a Março de 2006 segundo índices de trauma. Biosci. J. Uberlândia. 2009, 25 (2), 152 - 160.

12. Malvéstio MAA. Predeterminantes de sobrevivência em vítimas de acidente de trânsito submetidas a atendimento pré-hospitalar de suporte avançado à vida. Tese de Doutorado. Escola de Enfermagem da Universidade de São Paulo. São Paulo. 2005, 01 - 167.

13. Parreira JG, Gregorut F, Perlingeiro JAG, Solda SC, Assef JC. Análise comparativa entre as lesões encontradas em motociclistas envolvidos em acidentes de trânsito e vítimas de outros mecanismos de trauma fechado. Revista Associação Médica Brasileira. 2012, 8 (1), 76 - 81.

14. Ganne N, Martinez AT, Rodrigues C, Delgado MHC, Souza FA. Estudo sobre acidentes de trânsito envolvendo motocicletas, ocorridos no Município de Corumbá, Estado de Mato Grosso do Sul, Brasil, no ano 2010. Revista Pan-Amazônia Saúde. 2013, 4 (1), 15 - 22.

15. Nunes MN, Nascimento LFC. Análise espacial de óbitos por acidentes de trânsito, antes e depois da Lei Seca, nas microrregiões do estado de São Paulo. Rev. Assoc. Med. Bras. São Paulo. 2012, 58 (6), 685 - 690.

16. CRUZ MJA. Os impactos dos acidentes de trânsito por lesão corporal na vida dos vitimados em face ao controle social do estado. Dissertação (Mestrado em Desenvolvimento e Meio Ambiente Urbano) - Universidade da Amazônia, Belém, 2013, 01 - 104 